\title{
THE CHILD'S LEARNING OF ENGLISH MORPHOLOGY
}

\author{
JEAN BERKO
}

In this study ${ }^{1}$ we set out to discover what is learned by children exposed to English morphology. To test for knowledge of morphological rules, we use nonsense materials. We know that if the subject can supply the correct plural ending, for instance, to a noun we have made up, he has internalized a working system of the plural allomorphs in English, and is able to generalize to new cases and select the right form. If a child knows that the plural of witch is witches, he may simply have memorized the plural form. If, however, he tells us that the plural of * gutch is * gutches, we have evidence that he actually knows, albeit unconsciously, one of those rules which the descriptive linguist, too, would set forth in his grammar. And if children do have knowledge of morphological rules, how does this knowledge evolve? Is there a progression from simple, regular rules to the more irregular and qualified rules that are adequate fully to describe English? In very general terms, we undertake to discover the psychological status of a certain kind of linguistic description. It is evident that the acquisition of language is more than the storing up of rehearsed utterances, since we are all able to say what we have not practiced and what we have never before heard. In bringing descriptive linguistics to the study of language acquisition, we hope to gain knowledge of the systems and patterns used by the speaker.

In order to test for children's knowledge of this sort, it was necessary to begin with an examination of their actual vocabulary. Accordingly, the 1000 most frequent words in the first-grader's vocabulary were selected from Rinsland's listing. ${ }^{2}$ This listing

\footnotetext{
${ }^{1}$ This investigation was supported in part by a fellowship from the Social Science Research Council. During the academic year 1957-58 the writer completed the research while holding an AAUW National Fellowship. A dissertation on this subject was presented by the writer to Radcliffe College in April, 1958. I am. indebted to Professor Roger W. Brown for his inspiration and his help in the conduct of this study.

${ }^{2}$ H. D. Rinsland, A Basic Vocabulary of Elementary School Children, New York, MacMillan, 1945.
} 
contains the most common words in the elementary school child's vocabulary, as taken from actual conversations, compositions, letters, and similar documents. This list was then examined to see what features of English morphology seem to be most commonly represented in the vocabulary of the first-grade child. From this we could decide what kind of extensions we might expect the child to be able to make. All of the English inflectional morphemes were present.

The areas that seemed to be most promising from this examination were the plural and the two possessives of the noun, the third person singular of the verb, the progressive and the past tense, and the comparative and superlative of the adjective. The pronouns were avoided both because of the difficulty involved in making up a nonsense pronoun, and because the pronouns are so few in number and so irregular that we would hardly expect even adults to have any generalized rules for the handling of new pronouns. Moreover, we do not encounter new pronouns, whereas new verbs, adjectives, and nouns constantly appear in our vocabularies, so that the essential problem is not the same. The past participle of regular or weak verbs in English is identical with the past tense, and since the regular forms were our primary interest, no attempt was made to test for the past participle. A number of forms that might suggest irregular plurals and past tenses were included among the nouns and verbs.

The productive allomorphs of the plural, the possessive, and the third person singular of the verb are phonologically conditioned and identical with one another. These forms are /-s $-\mathrm{z}-\partial \mathrm{z} /$, with the following distribution:

/-əz/ after stems that end in/s z š č ĵ]/, e.g. glasses, watches;

$/$-s/ after stems that end in /p t $\mathrm{k} \mathrm{f} \Theta /$, e.g. hops, hits;

/-z/ after all other stems, viz. those ending in /b d g v $0 \mathrm{~m} \mathrm{n} \mathrm{\eta} \mathrm{l} /$, vowels, and semivowels, e.g. bids, goes.

The productive allomorphs of the past are $/ t \sim d \sim$ əd/, and they are also phonologically conditioned, with the following distribution:

/-əd/ after stems that end in /t d/, e.g. melted;

$/$-t/ after stems that end in /p k č f $\Theta \breve{s} /$, e.g. stopped;

/-d/ after stems ending in voiced sounds except/-d/. e.g. climbed, played.

The progressive -ing and the adjective -er and -est do not have variants. It might also be noted that the possessive has an 
additional allomorph /-Ø/; this occurs after an inflectional /s/ or $/-z /$, so that if the form boy is made plural, boys, the possessive of that plural form is made by adding nothing, and indicated in writing only by the addition of an apostrophe: boys'.

The children's vocabulary at the first-grade level also contains a number of words that are made of a free morpheme and a derivational suffix, e.g. teacher, or of two free morphemes, e.g. birthday. The d faculties encountered in this area are many. First, it might be noted that there are not many contrasts, i.e., not many cases of the same derivational suffix being added to different bases to produce forms of like function. Although beautiful and thankful both appear on the list, it does not seem that these examples are numerous enough for us to expect a young child to be able to append -ful to a new noun in order to produce an adjective. Word derivation and compounding are furthermore often accompanied by changes in stress and pronunciation, so that the picture is additionally complicated. There seemed to be enough examples of the stress pattern ' \as in bláckboàrd as against blàck boárd, and of the diminutive-affectionate $-y$, the adjectival $-y$, and the agentive -er to warrant testing for these forms.

So far as the general picture is concerned, all speakers of the language are constrained to use the inflectional endings and apply them appropriately to new forms when they are encountered. We are not so often called upon to derive or compound new words, although by the time we are adults we can all to some extent do this. From the children's actual vocabulary we were able to make an estimate of the kind of morphological rules they might be expected to possess, and from these items a test could be constructed. It was noted, moreover, that in the child's vocabulary there are a number of compound words, like blackboard and birthday. It is entirely possible to use a compound word correctly and never notice that it is made of two separate and meaningful elements. It is also possible to use it correctly and at the same time have a completely private meaning for one or both of its constituent elements. In order to see what kind of ideas children have about the compound words in their vocabularies, it was decided to ask them directly about a selected number of these words.

Within the framework of the child's vocabulary, a test was devised to explore the child's ability to apply morphological rules to new words. He was called upon to inflect, to derive, to compound, and, lastly, to analyse compound words. 


\section{MATERIALS AND PROCEDURE}

In order to test for the child's use of morphological rules of different types and under varying phonological conditions, a number of nonsense words were made up, following the rules for possible sound combinations in English. Pictures to represent the nonsense words were then drawn on cards. There were 27 picture cards, and the pictures, which were brightly colored, depicted objects, cartoon-like animals, and men performing various actions. For reasons that will be discussed later, several actual words were also included. A text, omitting the desired form, was typed on each card. An example of the card to test for the regular plural allomorph in $/-z /$ can be seen in Figure 1.

The subjects included 12 adults (seven women and five men), all of whom were college graduates. Many of these adults had also had some graduate training. All were native speakers of English.

The child subjects were obtained at the Harvard Preschool in Cambridge and the Michael Driscoll School, in Brookline, Massachusetts. At the Preschool, each child was brought to the experimenter, introduced, and told that now he was going to look at some pictures. The experimenter would point to the picture and read the text. The child would supply the missing word, and the item he employed was noted phonemically. After all of the pictures had been shown, the child was asked why he thought the things denoted by the compound words were so named. The general form of these questions was "Why do you think a blackboard is called a blackboard?" If the child responded with "Because it's a blackboard", he was asked, "But why do you think it's called that?" The children at the preschool ranged between four and five years in age. Twelve girls and seven boys were asked all items of the completed test, and two groups, one of three boys and three girls and one of five boys and three girls, were each asked half of the inflectional items in preliminary testing.

At the Driscoll School, the experimenter was introduced to the class and it was explained that each child was going to have a turn at looking at some pictures. The procedure from this point on was the same as for the Preschool. All children in the first grade were interviewed. There were 26 boys and 35 girls in this group. Ages ranged from five and one half to seven years. 


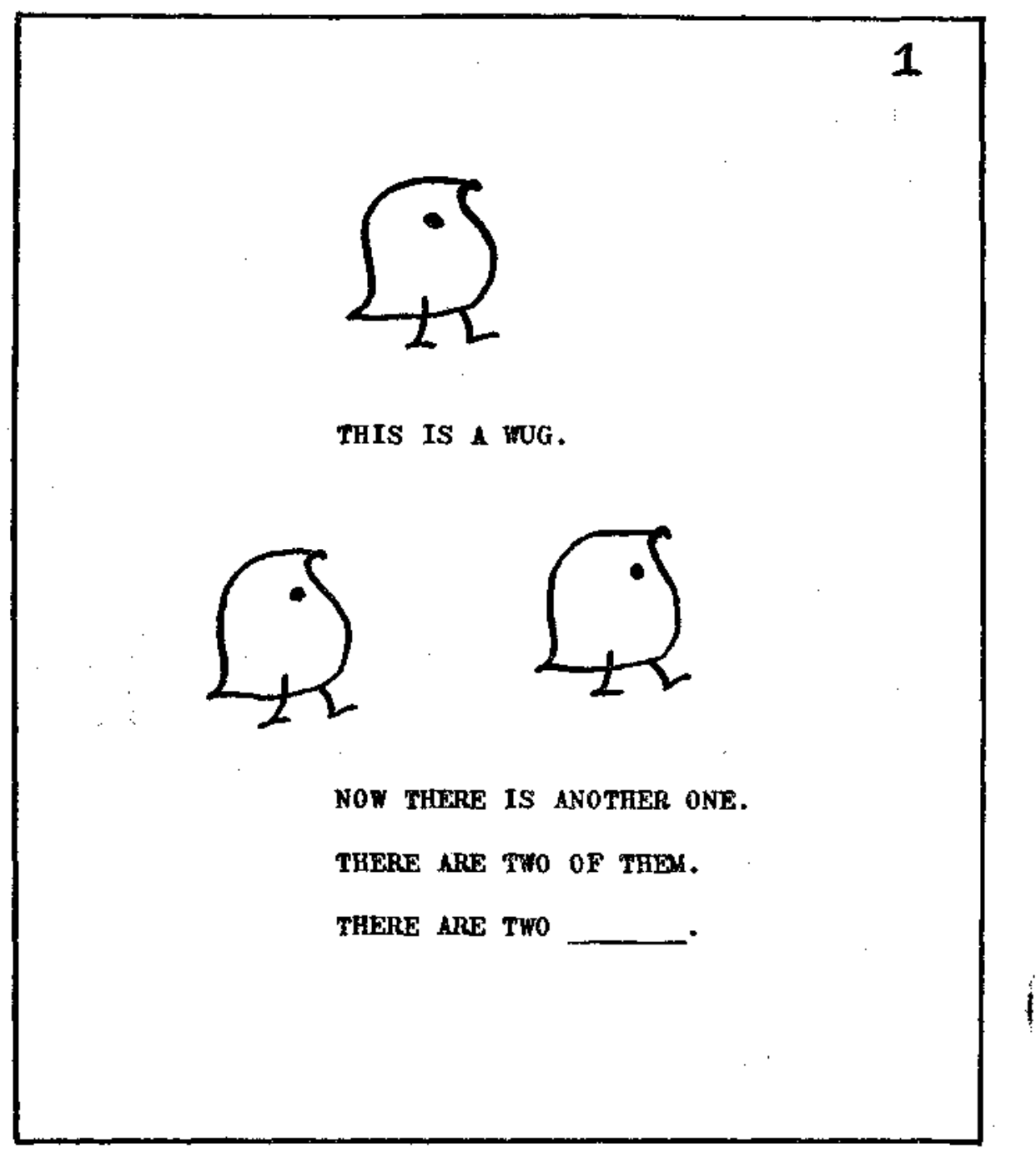

Figure 1. The plural allomorph in /-z/. 
The following is the order in which the cards were presented. Included is a statement of what was being tested, a description of the card, and the text that was read. Pronunciation is indicated by regular English orthography; a phonemic transcription is included for first occurrences of nonsense words.

1. Plural. One bird-like animal, then two. "This is a wug $/ \mathrm{w} \Lambda \mathrm{g} /$. Now there is another one. There are two of them. There are two

2. Plural. One bird, then two. "This is a gutch $/ \mathrm{g} \Lambda \mathrm{c} /$. Now there is another one. There are two of them. There are two "

3. Past tense. Man with a steaming pitcher on his head. "This is a man who knows how to spow /spow/. He is spowing. He did the same thing yesterday. What did he do yesterday? Yesterday he ."

4. Plural. One animal, then two. "This is a kazh / kæž/. Now there is another one. There are two of them. There are two ".

5. Past tense. Man swinging an object. "This is a man who knows how to rick $/ \mathrm{rlk} /$. He is ricking. He did the same thing yesterday. What did he do yesterday? Yesterday he

6. Diminutive and compounded or derived word. One animal, then a miniscule animal. "This is a wug. This is a very tiny wug. What would you call a very tiny wug? This wug lives in a house. What would you call a house that a wug lives in?"

7. Plural. One animal, then two. "This is a tor/tor/. Now there is another one. There are two of them. There are two

8. Derived adjective. Dog covered with irregular green spots. "This is a dog with quirks / kw $2 \mathrm{ks} /$ on him. He is all covered with quirks. What kind of dog is he? He is a dog."

9. Plural. One flower, then two. "This is a lun $/ 1 \Lambda \mathrm{n} /$. Now there is another one. There are two of them. There are Two '"

10. Plural. One animal, then two. "This is a niz /nIz/. Now there is another one. There are two of them. There are two

11. Past tense. Man doing calisthenics. "This is a man who 
knows how to mot $/ \mathrm{mat} /$. He is motting. He did the same thing yesterday. What did he do yesterday? Yesterday he

12. Plural. One bird, then two. "This is a kra $/ \mathrm{kra} /$. Now there is another one. There are two of them. There are two

13. Plural. One animal, then two. "This is a tass /tæs/. Now there is another one. There are two of them. There are Two

14. Past tense. Man dangling an object on a string. "This is a man who knows how to bod /bad/. He is bodding. He did the same thing yesterday. What did he do yesterday? Yesterday he

15. Third person singular. Man shaking an object. "This is a man who knows how to naz /næz/. He is nazzing. He does it every day. Every day he

16. Plural. One insect, then two. "This is a heaf/hiyf/. Now there is another one. There are two of them. There are two

17. Plural. One glass, then two. "This is a glass. Now there is another one. There are two of them. There are two

18. Past tense. Man exercising. "This is a man who knows how to gling /glin/. He is glinging. He did the same thingyesterday. What did he do yesterday? Yesterday he

19. Third person singular. Man holding an object. "This is a man who knows how to loodge /luwdž/. He is loodging. He does it every day. Every day he

20. Past tense. Man standing on the ceiling. "This is a man who knows how to bing /bin/. He is binging. He did the same thing yesterday. What did he do yesterday? Yesterday he

21. Singular and plural possessive. One animal wearing a hat, then two wearing hats. "This is a niz who owns a hat. Whose hat is it? It is the hat. Now there are two nizzes. They both own hats. Whose hats are they? They are the hats."

22. Past tense. A bell. "This is a bell that can ring. It is ringing. It did the same thing yesterday. What did it do yesterday? Yesterday it 
23. Singular and plural possessive. One animal wearing a hat, then two. "This is a wug who owns a hat. Whose hat is

it? It is the hat. Now there are two wugs. They both own hats. Whose hats are they? They are the ___ hats."

24. Comparative and superlative of the adjective. A dog with a few spots, one with several, and one with a great number. "This dog has quirks on him. This dog has more quirks on him. And this dog has even more quirks on him. This dog is quirky. This dog is And this dog is the "

25. Progressive and derived agentive or compound. Man balancing a ball on his nose. "This is a man who knows how to $\mathrm{zib} / \mathrm{zIb} /$. What is he doing? He is ____. What would you call a man whose job is to zib?"

26. Past tense. An ice cube, then a puddle of water. "This is an ice cube. Ice melts. It is melting. Now it is all gone. What happened to it? $"$

27. Singular and plural possessive. One animal wearing a hat, then two. "This is a bik/bIk/ who owns a hat. Whose hat is it? It is the hat. Now there are two biks. They both. own hats. Whose hats are they? They are the ___ hats."

28. Compound words. The child was asked why he thought the following were so named. (No pictures were used for these items.)
a. afternoon
b. airplane
c. birthday
d. breakfast
e. blackboard
h. handkerchief
f. fireplace
g. football
i. holiday
j. merry-go-round
k. newspaper
I. sunshine
m. Thanksgiving
n. Friday

It took between ten and fifteen minutes to ask a child all of these questions. Even the youngest children have had experience with picture books, if not actual training in naming things through pictures, and no child failed to understand the nature of the task before him. It was, moreover, evident that a great number of these children thought they were being taught new English words. It was not uncommon for a child to repeat the nonsense word immediately upon hearing it and before being asked any questions. Often, for example, when the experimenter said "This is a gutch", the child repeated, "Gutch". Answers 
were willingly, and often insistently, given. These responses will be discussed in the following section.

RESULTS

Adult answers to the inflectional items were considered correct answers, and it was therefore possible to rate the children's answers. In general, adult opinion was unanimous-everyone said the plural of *wug was *wugs, the plural of * gulch was *gulches; where the adults differed among themselves, except in the possessives, it was along the line of a common but irregular formation, e.g. *heaf became "heaves in the plural for many speakers, and in these cases both responses were considered correct. If a child said that the plural of *heaf was *heafs or "heaves /-vz/, he was considered correct. If he said *heaf (no ending), or *heafes/-fəz/, he was considered incorrect, and a record was kept of each type of response.

\section{SEX DIFFERENCES}

The first question to be answered was whether there is a sex difference in the ability to handle English morphology at this age level. Since it seemed entirely possible that boys entering the first grade might be on the whole somewhat older than girls entering the first grade, it was necessary to equate the two groups for age.

\begin{tabular}{lccc}
\multicolumn{4}{c}{ TABLE 1. DISTRIBUTION OF CHILDREN AT EACH } \\
FOR COMPARISON OF & THE & SEXES \\
Age & Boys & Girls & Total \\
4 & 2 & 2 & 4 \\
$4 ; 6$ & 1 & 1 & 2 \\
5 & 2 & 2 & 4 \\
$5: 6$ & 2 & 2 & 4 \\
6 & 10 & 10 & 20 \\
$6: 6$ & 6 & 6 & 12 \\
7 & 5 & 5 & 10
\end{tabular}

Total: $28.28 \quad 56$

The children were divided into seven age groups. Since at each of these levels there were more girls than boys, a random selection of the girls was made so that they would match the boys in number. The distribution of these ages and the number in 
each group can be seen in Table 1. This distribution was utilized only in comparing the performance of the boys with that of the girls; in all other instances, the responses of the entire sample were considered.

The groups of 28 boys and 28 girls thus selected were compared with one another on all inflectional items. The chi square criterion with Yates' correction for small frequencies was applied to each item, and on none was there a significant difference between the boys' and girls' performance; boys did as well as girls, or somewhat better, on over half the items, so that there was no evidence of the usual superiority of girls in language matters. From this it would appear that boys and girls in this age range are equal in their ability to handle the English morphology represented by these items.

\section{AGE DIFFERENCES}

Having ascertained that there was no difference between boys' and girls' answers, we combined the sexes and went on to compare the younger with the older children. The oldest children at the Preschool were five years old, and the youngest at the Driscoll School were five and one half years, so that the dividing line was made between the schools. Chi square corrected for small frequencies was again applied to all inflectional items. First graders did significantly better than preschoolers on slightly less than half of these. The differences can be seen in Table 2 .

TABLE 2. AGE DIFFERENCES ON INFLEXIONAL ITEMS

\begin{tabular}{|c|c|c|c|}
\hline $\begin{array}{l}\text { Item } \\
\text { school answers Plural }\end{array}$ & $\begin{array}{l}\text { Percentage of } \\
\text { correct pre- }\end{array}$ & $\begin{array}{l}\text { Percentage of } \\
\text { correct first- } \\
\text { grade answers }\end{array}$ & $\begin{array}{l}\text { Significance } \\
\text { level of } \\
\text { difference }\end{array}$ \\
\hline glasses .......................... & 75 & 99 & .01 \\
\hline wugs & 76 & 97 & .02 \\
\hline 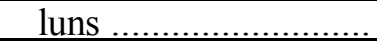 & 68 & 92 & .05 \\
\hline tors & 73 & 90 & - \\
\hline heafs & 79 & 80 & — \\
\hline eras ............ & 58 & 86 & .05 \\
\hline tasses ........... & 28 & 39 & - \\
\hline gutches & 28 & 38 & - \\
\hline kazhes & 25 & 36 & - \\
\hline nizzes . & 14 & 33 & - \\
\hline
\end{tabular}




\begin{tabular}{|c|c|c|c|}
\hline Item & $\begin{array}{l}\text { Percentage of } \\
\text { Correct pre- } \\
\text { School ans. }\end{array}$ & $\begin{array}{l}\text { Percentage of } \\
\text { correct } 1^{\text {st }} \\
\text { Grade ans }\end{array}$ & $\begin{array}{l}\text { Significance } \\
\text { level of diff. }\end{array}$ \\
\hline 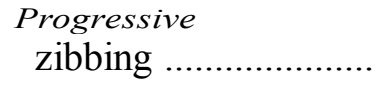 & 72 & 97 & .01 \\
\hline $\begin{array}{l}\text { Past Tense } \\
\text { binged .......... } \\
\text { glinged. .................. } \\
\text { ricked .......... } \\
\text { melted ......... } \\
\text { spowed ........ } \\
\text { motted ........ } \\
\text { bodded ........ } \\
\text { rang ............ }\end{array}$ & $\begin{array}{r}60 \\
63 \\
73 \\
72 \\
36 \\
32 \\
14 \\
0\end{array}$ & $\begin{array}{l}85 \\
80 \\
73 \\
74 \\
59 \\
33 \\
31 \\
25\end{array}$ & $\begin{array}{l}- \\
.05 \\
.01\end{array}$ \\
\hline 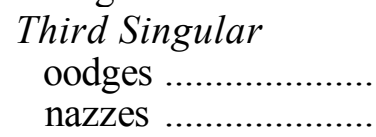 & $\begin{array}{c}57 \\
47\end{array}$ & $\begin{array}{c}56 \\
49\end{array}$ & - \\
\hline 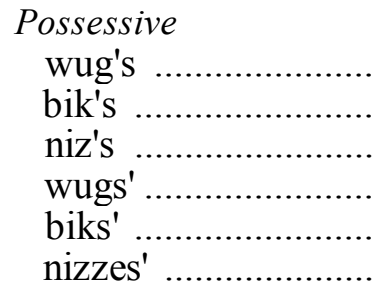 & $\begin{array}{c}68 \\
68 \\
58 \\
74 \\
74 \\
53\end{array}$ & $\begin{array}{c}81 * \\
95 \\
46 \\
97 \\
99 \\
82\end{array}$ & $\begin{array}{l}.02 \\
.01 \\
.05\end{array}$ \\
\hline
\end{tabular}

Formation of the Plural

The nature of the children's answers can best be seen through a separate examination of the noun plurals, the verbs, and the possessives. The percentage of all children supplying correct plural endings can be seen in Table 3 . The general picture indicates that children at this age have in their vocabularies words containing the three plural allomorphs $/-\mathrm{s} \sim-\mathrm{Z} \sim-\partial \mathrm{Z} /$, and can use these words. The real form glasses was included here because we knew from a pretest that children at this age generally did not make correct application of $/-\mathrm{-zz} /$ to new forms, and we wanted to know if they used this form with a common English word. Evidently they have at least one actual English model for this contingent plural. In uncomplicated cases children at this age can also extend the use of these forms to new words requiring 
/-s/ or $/-z /$, as indicated by the high percentage of right answers for *wug and *bik, a form used in the pretest and answered correctly by a correspondingly high number of children. For the items *wugs and glasses there is, moreover, a significant difference between the younger and older groups. For glasses they progress from $75 \%$ right to $99 \%$ right in the older group, a change that is significant at the $1 \%$ level. The few wrong answers in these cases were either a complete failure to respond, or a repetition of the word in its singular form.

TABLE 3. PERCENTAGES OF CHILDREN SUPPLYING CORRECT PLURAL FORMS

$\begin{array}{lll}\text { Item } & \text { Allomorph } & \text { \% Correct } \\ \text { glasses } & \text { zZ } & 91 \\ \text { wugs } & z & 91 \\ \text { luns } & z & 86 \\ \text { tors } & z & 85 \\ \text { heafs, -ves } & \mid-\mathrm{s} / /-\mathrm{z} / & 82 \\ \text { kras } & \mathrm{Z} & 79 \\ \text { tasses } & \text { oz } & 36 \\ \text { gutches } & \text { oz } & 36 \\ \text { kazhes } & \text { zZ } & 31 \\ \text { nizzes } & \text { oz } & 28\end{array}$

From this it is evident that however poorly children may do on extensions of the rule for forming the plural of glass, they do have this item in their vocabulary and can produce it appropriately. During the period from preschool to the first grade, those who do not have this item acquire it. They can also extend the rule for the addition of the $/-\mathrm{s} /$ or $/-\mathrm{z} /$ allomorph where the more general rules of English phonology dictate which of these forms must be used. During this period they perfect this knowledge.

The ability to add /-z/ to *wug and /-s/ to *bik does not alone prove that the child possesses the rule that tells which allomorph of the plural must be used: English phonology decrees that there cannot be a consonant cluster $* /-\mathrm{kz} /$ or $* /$-gs/. The final consonant determines whether the sibilant must be voiced or unvoiced. The instances in English where there is a choice are after $/ ! / / \mathrm{n} /$ and $/ \mathrm{r} /$, and after a vowel or semivowel. Thus we have minimal pairs like: ells: else; purrs: purse; hens: hence; pews: puce. In forming the plural of *wug or *bik, the child has only to know 
that a dental sibilant must be added; which one it is is determined by the invariant rules of combination that govern English consonant clusters. If, however, he is faced with a new word ending in a vowel, semivowel, /-I/, /-n/, or /-r/, he himself must make the choice, because so far as English phonology is concerned he could add either a /-z/ or an /-s/ and still have a possible English word. We would expect him, therefore, to have more difficulty forming the plural of a new word ending in these sounds than in cases where phonology determines the form of the sibilant. These problems are represented by the forms *cra, *tor, and *lun. As table 3 indicates, the percentages correct on these items were respectively 79,85 , and 86 . The difference between performance on *wug and "cra is significant at the $5 \%$ level.

During the period from preschool to the first grade, they improved markedly in their handling of *cra and *lun. The differences between the younger and older groups were significant at the $5 \%$ level. The case of adding /-s/ to these forms did not, however, arise. The child here, as in so many other stages of language learning, answered complexity with silence: the wrong answers were invariably the unaltered form of the singular.

The only other case to be answered correctly by the majority of the children was *heaf. Since adults responded with both *heafs and * heaves /-vz/, both of these answers were considered correct. It must be noted that although $42 \%$ of the adults gave *heaves as the plural of this item, employing what would amount to a morphophonemic change along the lines of: knife: knives; hoof: hooves, only three children out of a total of 89 answering this item said "heaves; 9, or $10 \%$ added nothing, and an additional four formed the plural with the wrong allomorph, i.e. they said /hiyfəz/, treating the /-f/ as if it belonged to the sibilant-affricate series. /f/ is, of course, phonetically very similar to /s/, and one of the questions suggested by this problem was whether children would generalize in the direction of phonetic similarity across functional boundaries-/f/ is distinguished phonetically from /s/ only in that it is grave and $/ \mathrm{s} /$ is acute. It is, so to speak, no more different from $/ \mathrm{s} /$ than $/ \mathrm{z} /$ is, and it is as similar to $/ \mathrm{s} /$ as $/ \mathbf{z} /$ is to $/ z /$. It does not, however, so far as English phonology is concerned, function like /s $\breve{s} \mathrm{z} \breve{\mathrm{z}} \breve{c} \hat{\mathrm{j}} /$, none of which can be immediately followed by another sibilant within the same consonant cluster. The high percentage of correct items indicates that /f/ had already been categorized as belonging to the consonant class that can be followed by /-s/, and the phonetic similarity 
between /f/ and the sibilants did not lead the children to generalize the rule for the addition of the /-əz/ allomorph in that direction. Nor could any irregular formation be said to be productive for children in this case, although for adults it apparently is.

The proportion of children's right answers suddenly drops when we come to the form *tass. As table 3 shows, $91 \%$ of these children when given the form glass could produce the form glasses. When given the form *tass, a new word patterned after glass, only $36 \%$ could supply the form Classes. The picture becomes progressively worse with the other words ending in sibilants or affricates, and by the time we reach the form *niz, only $28 \%$ answered correctly. *Niz of these four, is the only one that ends in a sound that is also the commonest plural allomorph, /-z/, and the children did the worst on this item. What is of additional interest, is that on these four items there was no significant improvement from the preschool to the first grade. The difference between performance on *cra, the worst of the other items, and *tass, the best of these, was significant at the .1\% level. Again, the wrong answers consisted in doing nothing to the word as given. It must be noted, however, that in these items, the children delivered the wrong form with a great deal of conviction: $62 \%$ of them said "one *lass, two "lass" as if there were no question that the plural of *tass should and must be *lass. From this it is evident that the morphological rules these children have for the plural are not the same as those possessed by adults: the children can add /-s/ or /-z/ to new words with a great deal of success. They do not as yet have the ability to extend the /-əz/ allomorph to new words, even though it has been demonstrated that they have words of this type in their vocabulary.

The form "kazh" /kaž/ was added here once again to see in what direction the children would generalize. /z/, although it is in the sibilant-affricate group, is very rare as a final consonant in English: it occurs only in some speakers' pronunciation of garage, barrage, and a few other words. As table 3 indicates, the children treated this word like the others of this group. It might also be noted here that for the forms *gulch and *kazh, some few children formed the plural in /-s/, i.e., /g $\Lambda$ č/ and $/ \mathrm{kæž/.} 10 \%$ did this for *gulch, and $5 \%$ for *kazh, errors that indicate that the phonological rules may not yet be perfectly learned. What is clearest from these answers dealing with the plural is that children can and 
do extend the /-s/ and /-z/ forms to new words, and that they cannot apply the more complicated /-əz/ allomorph of the plural to new words.

\section{VERB INFLECTIONS}

The children's performance on the verb forms can be seen in Table 4. It will be observed that the best performance on these items was on the progressive, where they were shown a picture of a man who knew how to $*_{z i b}$ and were required to say that he was

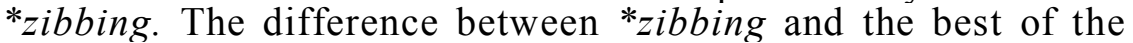
past tense items, "hinged, was significant at the $5 \%$ level. The improvement from the younger to the older group was significant at the $1 \%$ level; fully $97 \%$ of the first graders answered this question correctly. Here, there was no question of choice, there is only one allomorph of the progressive morpheme, and the child either knows this -ing form or does not. These results suggest that he does.

The results with the past tense forms indicate that these children can handle the /-t/ and /-d/ allomorphs of the past. On * hinged and * glinged the percentages answering correctly were 78 and 77 , and the older group did significantly better than the younger group on * hinged.

TABLE 4. PERCENTAGES OF CHILDREN SUPPLYING CORRECT VERB FORMS

$\begin{array}{lcc}\text { Item } & \text { Allomorph } & \text { Percentage Correct } \\ \begin{array}{l}\text { Progressive } \\ \text { zibbing }\end{array} & \text { /-in/ } & 90 \\ \text { Past Tense } & & \\ \text { binged, bang } & /-\mathrm{d} \sim \mathfrak{} / & 78 \\ \text { glinged, glang } & /-\mathrm{d} \sim \text { ce/ } & 77 \\ \text { ricked } & /-\mathrm{t} / & 73 \\ \text { melted } & /-\mathrm{ad} / & 53 \\ \text { spowed } & /-\mathrm{d} / & 33 \\ \text { motted } & /-\mathrm{od} / & 31 \\ \text { bodded } & /-\mathrm{od} / & 17 \\ \text { rang } & / \mathrm{ae} / & 56 \\ \text { Third Singular } & & 48 \\ \text { loodges } & /-\mathrm{zz} / & \\ \text { nazzes } & /-\mathrm{oz} / & \end{array}$


Actually, the forms * gling and *bing were included to test for possible irregular formations. A check of English verbs revealed that virtually all in -ing form their past tense irregularly: sing: sang; ring: rang; cling: clung, and many others. The only ing verbs that form a past tense in -ed are a few poetic forms like enringed, unkinged, and winged, and onomotopoeias like pinged and zinged. Adults clearly felt the pull of the irregular pattern, and $50 \%$ of them said *bang or *bung for the past tense of *bing, while $75 \%$ made *gling into *glang or *glung in the past. Only one child of the 86 interviewed on these items said *bang. One also said * glang, and two said * glanged-changing the vowel and also adding the regular /-d/ for the past.

The great majority on these forms, as well as on *ricked which requires /- $t$ /, formed the past tense regularly. There was a certain amount of room for variation with the past tense, since there is more than one way of expressing what happened in the past. A number of children, for example said "Yesterday he was *ricking". If on these occasions the experimenter tried to force the issue by saying "He only did it once yesterday, so yesterday once he-?" The child usually responded with "once he was *ricking". Taking into account this possible variation, the percentages right on *rick, *gling and *bing represent a substantial grasp of the problem of adding a phonologically determined /-t/ or $/-\mathrm{d} /$.

With *spow the child had to choose one or the other of the allomorphs, and the drop to $52 \%$ correct represents this additional complexity. Several children here retained the inflectional /-z/ and said /spowzd/, others repeated the progressive or refused to answer. No child supplied a $/-t /$.

On *motted, the percentage correct drops to 33 , although the subjects were $73 \%$ right on the real word melted, which is a similar form. On *bodded they were $31 \%$ right, and on rang only $17 \%$ right. The older group was significantly better than the younger on rang and *bodded. What this means is that the younger group could not do them at all - not one preschool child knew rangand the older group could barely do them. What emerges here is that children at this age level are not able to extend the rule for forming the past tense of melted to new forms. They can handle the regular /-d/ and /-t/ allomorphs of the past in new instances, but not /-əd/. Nor do they have control of the irregular past form rang, and consequently do not form new pasts according to this pattern, although adults do. They have the /-əd/ form in actual 
words like melled, but do not generalize from it. With ring, they do not have the actual past rang, and, therefore no model for generalization. In the children's responses, the difference between *spowd, the worst of the items requiring /- $t /$ or $/-\mathrm{d} /$, and * molted, the best requiring/-əd/ is significant at the $2 \%$ level. For *mot and *bod, the wrong answers, which were in the majority, were overwhelmingly a repetition of the present stem: "Today he* bods; yesterday he *bod." To the forms ending in /-t/ or /-d/ the children added nothing to form the past.

The third person singular forms require the same allomorphs as the noun plurals, $/-\mathrm{s} \sim \mathrm{Z} \sim 2 \mathrm{~d} /$, and only two examples were included in the experiment. These were *loodge and *naz, and required the $/-\partial z /$ ending. $56 \%$ of the children supplied the correct form "loodges, and $48 \%$ supplied *nazzes. The wrong answers were again a failure to add anything to the stem, and there was no improvement whatsoever from the younger to the older group on these two items.

\section{FORMATION OF THE POSSESSIVE}

The only other inflectional items statistically treated were the regular forms of the possessive. The percentages of children supplying right answers can be seen in Table 5. In the singular, the problem was the same as for the noun plurals, and the children's difficulty with the /-əz/ form of the allomorph is mirrored in the low percentage who were able to supply *niz's /-əz/ when told "This is a niz who owns a hat. Whose hat is it? It is the_?" For "*bik's there was a significant improvement at the $2 \%$ level between the younger and older groups. For *niz's the younger group did no worse than the older group.

In the plural possessives the problem is somewhat different: since these words are already regularly inflected, the possessive is formed by adding a morphological zero. The children did not add an additional /-əz/ to these forms, and in the case of *nizzes', they erred on the side of removing the plural -es, e.g. for the plural possessive they said, simply *niz in those cases where they gave the wrong answers.

It was the adults who had difficulty with the plural possessives: $33 \%$ of them said *wugses /-zəz/ and *bikses /-səz/, although none said *nizeses /-əzəz/. This is undoubtedly by analogy with proper nouns in the adults' vocabulary, i.e., no adult would say that if two dogs own hats, they are the *dogses /-zəz/ hats. However 
an adult may know a family named Lyons, and also a family named Lyon. In the first instance, the family are the Lyonses /zaz/ and if they own a house, it is the Lyonses'/-zoz/ house; in the second instance, the family are the Lyons and their house is the Lyons' $\mid-n z /$. The confusion resulting from competing forms like these is such that some speakers do not make this distinction, and simply add nothing to a proper noun ending in $/-\mathrm{s} /$ or $/-z /$ in order to form the possessive - they say "it is Charles'/-lz/ hat". Some speakers seem also to have been taught in school that they must use this latter form. It seems likely that the children interviewed had not enough grasp of the /-oz/ form for these niceties to affect them.

TABLE 5. PERCENTAGES OF CHILDREN SUPPLYING CORRECT POSSESSIVE FORMS

$\begin{array}{lcc}\text { Singular } & \text { Allomorph } & \text { Percentage Correct } \\ \text { wug's } & \text { /-z/ } & 84 \\ \text { bik's } & \text { /-s/ } & 87 \\ \text { niz's } & \text { /-əz/ } & 49 \\ \text { Plural } & & \\ \text { wugs' } & \varnothing & 88 \\ \text { biks' } & \varnothing & 93 \\ \text { nizzes' } & \varnothing & 76\end{array}$

\section{ADJECTIVAL INFLEXION}

The last of the inflectional items involved attempting to elicit comparative and superlative endings for the adjective *quirky. The child was shown dogs that were increasingly "quirky and expected to say that the second was *quirkier than the first, and that the third was the *quirkiest. No statistical count was necessary here since of the 80 children shown this picture, only one answered with these forms. Adults were unanimous in their answers. Children either said they did not know, or they repeated the experimenter's word, and said "*quirky, too". If the child failed to answer, the experimenter supplied the form *quirkier, and said "This dog is quirky. This dog is quirkier. And this dog is the ?" Under these conditions $35 \%$ of the children could supply the -est form.

DERIVATION AND COMPOUNDING

The children were also asked several questions that called for 
compounding or deriving new words. They were asked what they would call a man who *zibbed for a living, what they would call a very tiny "wug, what they would call a house a *wug lives in, and what kind of dog a dog covered with *quirks is.

Adults unanimously said that a man who $*_{z i b s}$ is a $*_{z i b b e r}$ using the common agentive pattern -er. Only $11^{\circ}$ children said *zibber. Thirty-five percent gave no answer. 11 percent said $*_{z i b b i n g m a n}$ and $5 \%$ said $*_{z i b m a n}$, compounds that adults did not utilize. The rest of the children's answers were real words like clown or acrobat.

For the diminutive of *wug, $50 \%$ of the adults said *wuglet. Others offered little *wug, *wuggie, *wugette, and *wugling. No child used a diminutive suffix. $52 \%$ of the children formed compounds like baby *wug, teeny *wug, and little *wug. Two children, moreover, said a little $*_{w u g}$ is a *wig, employing sound symbolism - a narrower vowel to stand for a smaller animal. For the house a *wug lives in, $58 \%$ of the adults formed the asyntactic compound *wughouse. Others said *wuggery, *wugshouse, and *wughut. Again, no child used a suffix. The younger children did not understand this question, and where the older children did, they formed compounds. $18 \%$ of the first graders said *wughouse. Others suggested birdcage and similar forms. What emerges from this picture is the fact that whereas adults may derive new words, children at this stage use almost exclusively a compounding pattern, and have the stress pattern ${ }^{\mathrm{M}}$ at their disposal: the adults unanimously said that a dog covered with *quirks is a "quirky dog. $64 \%$ of the children formed the compound * quirk dog for this item, and again, no child used a derivational suffix.

\section{ANALYSIS OF COMPOUND WORDS}

After the child had been asked all of these questions calling for the manipulation of new forms, he was asked about some of the compound words in his own vocabulary; the object of this questioning was to see if children at this age are aware of the separate morphemes in compound words. The children's explanations fall roughly into four categories. The first is identity: "a blackboard is called a blackboard because it is a blackboard." The second is a statement of the object's salient function or feature: "a blackboard is called a blackboard because you write on it." In the third type of explanation, the salient feature 
happens to coincide with part of the name: "a blackboard is called a. blackboard because it is black;" "a merry-go-round is called a merry-go-round because it goes round and round". Finally, there is the etymological explanation given by adults - it takes into account both parts of the word, and is not necessarily connected with some salient or functional feature: "Thanksgiving is called Thanksgiving because the pilgrims gave thanks."

Of the children's answers, only $13 \%$ could be considered etymological. Most of their answers fell into the salient-feature category, while the number of identity responses dropped from the younger to the older group. Many younger children offered no answers at all; of the answers given, $23 \%$ were identity. Of the older children, only $9 \%$ gave identity answers, a difference that was significant at the $1 \%$ level.

As we might expect, the greatest number of etymological responses-23\%-was given for Thanksgiving, which is an item that children are explicitly taught. It must be noted, however, that despite this teaching, for $67 \%$ of the children answering this item, Thanksgiving is called Thanksgiving because you eat lots of turkey.

The salient feature answers at first seem to have the nature of an etymological explanation, in those instances where the feature coincides with part of the name-72\% of the answers, for instance, said that a fireplace is called a fireplace because you put fire in it. When the salient feature does not coincide with part of the name, however, the etymological aspects also drop out. For birthday, where to the child neither the fact that it is a day nor that it is tied to one's birth is important, the number of functional answers rises: it is called birthday because you get presents or eat cake. Only $2 \%$ said anything about its being a day.

The child approaches the etymological view of compound word through those words where the most important thing about the word so far as the child is concerned coincides with part of the name. The outstanding feature of a merry-go-round is that it does, indeed, go round and round, and it is the eminent appropriateness of such names that leads to the expectation of meaningfulness in other compound words.

Although the number of etymological explanations offered by the children was not great, it was clear that many children have what amounts to private meanings for many compound words. These meanings may be unrelated to the word's history, and 
unshared by other speakers. Examples of this can be seen in the following.

"An airplane is called an airplane because it is a plain thing that goes in the air."

"Breakfast is called breakfast because you have to eat it fast when you rush to school."

"Thanksgiving is called that because people give things to one another." (Thingsgiving?)

"Friday is a day when you have fried fish."

"A handkerchief is a thing you hold in your hand, and you go 'kerchoo'."

These examples suffice to give the general nature of the private meanings children may have about the words in their vocabulary. What is of additional interest, is that the last explanation about the handkerchief was also offered by one of the college-graduate adult subjects.

We must all learn to handle English inflection and some of the patterns for derivation and compounding. So long as we use a compound word correctly, we can assign any meaning we like to its constituent elements.

\section{CONCLUSION}

In this experiment, preschool and first grade children, ranging from four to seven years in age, were presented with a number of nonsense words and asked to supply English plurals, verb tenses, possessives, derivations and compounds of those words. Our first and most general question had been: do children possess morphological rules? A previous study of the actual vocabulary of first graders showed that they know real items representing basic English morphological processes. Asking questions about real words, however, might be tapping a process no more abstract than rote memory. We could be sure that our nonsense words were new words to the child, and that if he supplied the right morphological item he knew something more than the individual words in his vocabulary: he had rules of extension that enabled him to deal with new words. Every child interviewed understood what was being asked of him. If knowledge of English consisted of no more than the storing up of many memorized words, the child might be expected to refuse to answer our questions on the grounds that he had never before heard of a *wug, for instance, and could not possibly give us the plural form since no one 
had ever told him what it was. This was decidedly not the case. The children answered the questions; in some instances they pronounced the inflectional endings they had added with exaggerated care, so that it was obvious that they understood the problem and wanted no mistake made about their solution. Sometimes, they said "That's a hard one," and pondered a while before answering, or answered with one form and then corrected themselves. The answers were not always right so far as English is concerned; but they were consistent and orderly answers, and they demonstrated that there can be no doubt that children in this age range operate with clearly delimited morphological rules.

Our second finding was that boys and girls did equally well on these items. Sometimes the girls had a higher percentage of right answers on an item, and more often the boys did somewhat better, but no pattern of differences could be distinguished and the differences were never statistically significant. These findings are at variance with the results of most other language tests. Usually, girls have been shown to have a slight advantage over boys. In our experiment, girls were no more advanced than boys in their acquisition of English morphology. Since other language tests have not investigated morphology per se, it is easy enough to say that this is simply one area in which there are no sex differences. A reason for this lack of difference does, however, suggest itself: and that is the very basic nature of morphology. Throughout childhood, girls are perhaps from a maturational point of view slightly ahead of the boys who are their chronological age mates. But the language differences that have been observed may be culturally induced, arid they may be fairly superficial. Some social factor may lead girls to be more facile with words, to use longer sentences, and to talk more. This can be misleading. A girl in an intellectual adult environment may, for instance, acquire a rather sophisticated vocabulary at an early age. This should not be taken to mean that she will learn the minor rules for the formation of the plural before she learns the major ones, or that she will necessarily be precocious in her acquisition of those rules. What is suggested here is that every child is in contact with a sufficiently varied sample of spoken English in order for him to be exposed at an early age to the basic morphological processes. These processes occur in simple sentences as well as in complex ones. Practice with a limited vocabulary may be as effective as practice with an extensive vocabulary, and the 
factors that influence other aspects of language development may have no effect on morphological acquisition. Since, moreover, this type of inner patterning is clearly a cognitive process, we might expect it to be related to intelligence more than to any other feature. Unfortunately, there were no IQs available for the subjects, so that a comparison could not be made, and this lastmust remain a speculation.

Our next observation was that there were some differences between the preschoolers and the first graders. These were predominantly on the items that the group as a whole did best and worst on: since no child in the preschool could supply the irregular past rang, and a few in the first grade could, this difference was significant. Otherwise, the improvement was in the direction of perfecting knowledge they already had - the simple plurals and possessives, and the progressive tense. The answers of the two groups were not qualitatively different: they both employed the same simplified morphological rules. Since this was true, the answers of both groups were combined for the purpose of further analysis.

Children were able to form the plurals requiring /-s/ or /-z/, and they did best on the items where general English phonology determined which of these allomorphs is required. Although they have in their vocabularies real words that form their plural in $/-\partial z /$ in the age range that was interviewed they did not generalize to form new words in $/-\partial z /$. Their rule seems to be to add $/-s /$ or $/-z /$, unless the word ends in $/ \mathrm{s} \mathrm{z} \breve{s} \check{c} \check{z} \hat{\jmath} /$. To words ending in these sounds they add nothing to make the plural-and when asked to form a plural, repeat the stem as if it were already in the plural. This simplification eliminates the least common of the productive allomorphs. We may now ask about the relative status of the remaining allomorphs $/-\mathrm{s} /$ and $/-\mathrm{z} /$. For the items like *lun or *cra, where both of these sounds could produce a phonologically possible English word, but not a plural, no child employed the voiceless alternant $/-\mathrm{s} /$. This is the second least common of the three allomorphs. The only places where this variant occurred were where the speaker of English could not say otherwise. So far as general English phonology is concerned a $/-\mathrm{z} /$ cannot in the same cluster follow a /-k-/ or other voiceless sound. Once the /-k-/ has been said, even if the speaker intended to say $/-z /$, it would automatically devoice to $/-\mathrm{s} /$. The only morphological rule the child is left with, is the addition of the /-z/ allomorph, which is the most extensive: the /-oz/ form for him 
is not yet productive, and the /-s/ form can be subsumed under a more general phonological rule.

What we are saying here is that the child's rule for the formation of the plural seems to be: "a final sibilant makes a word plural". The question that arises is, should we not rather say that the child's rule is: "a voiceless sibilant after a voiceless consonant and a voiced sibilant after all other sounds makes a word plural." This latter describes what the child actually does. However, our rule will cover the facts if it is coupled with a prior phonological rule about possible final sound sequences. The choice of the voiceless or voiced variant can generally be subsumed under phonological rules about final sound sequences; the exceptions are after vowels, semivowels, and $/ 1-n-r-/$. In these places where phonology leaves a choice, /-z/ is used, and so the child's conscious rule might be to add $/-z /$. It would be interesting to find out what the child thinks he is saying-if we could in some way ask him the general question, "how do you make the plural?"

Another point of phonology was illustrated by the children's treatment of the forms *heaf and *kazh. It was demonstrated here that the children have phonological rules, and the direction of their generalizations was dictated by English phonology, and not simple phonetic similarity. /-̌̌ / is a . comparatively rare phoneme, and yet they apparently recognized it as belonging to the sibilant series in English, and they rarely attempted to follow it with another sibilant. The similarity between /f/ and the sibilants, did not, on the contrary cause them to treat it as a member of this class. The final thing to be noted about *heaf is that several children and many adults said the plural was * heaves. This may be by analogy with leaf: leaves. If our speculation that the $\mid-z /$ form is the real morphological plural is right, there may be cases where instead of becoming devoiced itself, it causes regressive assimilation of the final voiceless consonant.

The allomorphs of the third person singular of the verb and the possessives of the noun are the same as for the noun plural, except that the plural possessives have an additional zero allomorph. These forms were treated in the same way by the children, with one notable exception: they were more successful in adding the /-əz/ to form possessives and verbs than they were in forming noun plurals. They were asked to produce three nearly identical forms: a man who *nazzes; two * nizzes; and a *niz's hat. On the verb they were $48 \%$ right; on the possessive they were $49 \%$ right, and on the noun plural they were only $28 \%$ right. The 
difference between their performance on the noun plural and on the other two items was significant at the $1 \%$ level. And yet the phonological problem presented by these three forms was the same. For some reason the contingent rule for the formation of the third person singular of the verb and for the possessive is better learned or earlier learned than the same rule for the formation of noun plurals. The morphological rule implies meaning, and forms that are phonologically identical may be learned at different times if they serve different functions. These forms are not simply the same phonological rule, since their different functions change the percentage of right answers. Perhaps the child does better because he knows more verbs than nouns ending in /s z š $\check{\mathrm{z}} \check{\mathrm{c}} \hat{\mathrm{j}} /$, and it is possible that he has heard more possessives than noun plurals. It is also possible that for English the noun plural is the least important or most redundant of these inflexions. This is a somewhat surprising conclusion, since nouns must always appear in a singular or plural form and there are ways of avoiding the possessive inflexion: it is generally possible to use an of construction in place of a possessive-we can say the leg of the chair or the chair's leg, or the chair leg although in cases involving actual ownership we do not say of. A sentence referring to the hat of John sounds like an awkward translation from the French. Arid no child said it was the hat of the *niz. The children's facility with these forms seems to indicate that the possessive inflection is by no means dying out in English.

Of the verb forms, the best performance was with the present progressive: $90 \%$ of all the children said that a man who knew how to $*_{z i b}$ was $*_{z i b b i n g}$. Undoubtedly, children's speech is mostly in the present tense, and this is a very commonly-heard form. Explanations of what is happening in the present all take this form. "The man is running" — or walking or eating or doing something. The additional point is that the -ing forms are not only very important; this inflection has only one allomorph. The rules for its application are completely regular, and it is the most general and regular rules that children prefer.

The children's handling of the past tense parallels their treatment of the plurals, except that they did better on the whole with the plurals. Again, they could not extend the contingent rule. Although they have forms like melted in their vocabulary, they were unable to extend the /-ad/ form to new verbs ending in $/ \mathrm{t} d /$. They treated these forms as if they were already in the past. They applied the allomorphs /-d/ and /-t/ appropriately where they 
were phonologically conditioned, and only /-d/ to a form like *spow, where either was possible. This suggests that their real morphological rule for the formation of the past is to add /-d/, and under certain conditions it will automatically become /-t/. Many adult speakers feel that they are adding a /-d/ in a word like stopped; this may be because of the orthography, and it may be because they are adding a psychological /-d/ that devoices without their noticing it.

Whereas the children all used regular patterns in forming the past tense, we found that for adults strong pasts of the form rang and clung are productive. Since virtually all English verbs that are in the present of an -ing form make their pasts irregularly, this seemed a likely supposition. Adults made *gling and *bing into *glang and *bang in the past. New words of this general shape may therefore be expected to have a very good chance of being treated according to this pattern - real words like the verb to siring for instance, have been known the vacillate between the common productive past and this strong subgroup and finally come to be treated according to the less common pattern. The children, however, could not be expected to use this pattern since we could not demonstrate that they had the real form rang in their repertory. They said "ringed. At one point, the experimenter misread the card and told the child that the bell rang. When the child was asked what the bell did, he said, "It * ringed." The experimenter then corrected him and said, "You mean it rang." The child said that was what he had said, and when asked again what that was, he repeated, "It ringed," as if he had not even heard the difference between these two allomorphs. Perhaps he did not.

The adults did not form irregular pasts with any other pattern, although a form was included that could have been treated according to a less common model. This was the verb *mot, which was of the pattern cut or bet. There are some 19 verbs in English that form their past with a zero morpheme, but this group does not seem to be productive.

The cases of * gling, which became * glang in the past and "mot, which became * motted suggest some correlates of linguistic productivity. About nineteen verbs in English form their past tense with a zero allomorph. About 14 verbs form their past like cling, and seven follow the pattern of ring. Within these last two groups there are words like win, which becomes won and swim, which becomes swam. We can also find words similar to 
win and swim that are quite regular in the past: pin and trim. But virtually all of the verbs that end in -ing form their past in ang or -ung. There are approximately 10 of these -ing verbs. The productivity of the -ang and -ung forms proves that new forms are not necessarily assimilated to the largest productive class. Where a small group of common words exist as a category by virtue of their great phonetic similarity and their morphological consistency, a new word having the same degree of phonetic similarity may be treated according to this special rule. $O x$ : oxen is not similarly productive, but probably would be if there were just one other form like box : boxen, and the competing fox : foxes did not exist. With *mot, the zero allomorph is not productive because although it applies to more cases than are covered by the -ing verbs, it is not so good a rule in the sense that it is not so consistent. The final / $/ \mathrm{t} /$, which is the only common phonetic element, does not invariably lead to a zero allomorph, as witness pit : pitted, pat : patted, and many others.

Although the adults were uniform in their application of -er and -est to form the comparative and superlative of the adjective, children did not seem to have these patterns under control unless they were given both the adjective and the comparative form. With this information, some of them could supply the superlative. Derivation is likewise a process little used by children at this period when the derivational endings would compete with the inflectional suffixes they are in the process of acquiring. Instead, they compound words, using the primary and tertiary accent pattern commonly found in words like blackboard.

The last part of the experiment was designed to see if the children were aware of the separate elements in the compound words in their vocabulary. Most of these children were at the stage where they explained an object's name by stating its major function or salient feature: a blackboard is called a blackboard because you write on it. In the older group, a few children had noticed the separate parts of the compound words and assigned to them meanings that were not necessarily connected with the word's etymology or with the meaning the morphemes may have in later life. Not many adults feel that Friday is the day for frying things, yet a number admit to having thought so as children.

These last considerations were, however, tangential to the main problem of investigating the child's grasp of English morphological rules and describing the evolution of those rules. The picture that emerged was one of consistency, regularity, and simplicity. The 
children did not treat new words according to idiosyncratic pattern. They did not model new words on patterns that appear infrequently. Where they provided inflectional endings, their best performance was with those forms that are the most regular and have the fewest variants. With the morphemes that have several allomorphs, they could handle forms calling for the most common of those allomorphs long before they could deal with allomorphs that appear in a limited distribution range.

Massachusetts Institute of Technology. 